\title{
Water Droplets Behavior in Extinguishing Methane-Air Counterflow Diffusion Flames
}

\author{
AKIRA YOSHIDA ${ }^{1}$, TORU UENDO ${ }^{1}$, RYOHEI TAKASAKI $^{1}$, HIROYOSHI NAITO $^{2}$, and YUKO \\ SASO $^{3}$ \\ ${ }^{1}$ Department of Mechanical Engineering \\ Tokyo Denki University \\ 2-2 Kanda-Nishikicho, Chiyoda-ku, Tokyo, Japan \\ ${ }^{2}$ Fire and Disaster Management Agency \\ 2-1-2 Kasumigaseki, Chiyoda-ku, Tokyo, Japan \\ ${ }^{3}$ National Research Institute of Fire and Disaster \\ 4-35-3 Jindaiji-Higashimachi, Chofu, Tokyo, Japan
}

\begin{abstract}
The behavior of fine water droplets was investigated in a methane-air counterflow diffusion flame, specifically when the water droplets were added to the inlet air feed and used to extinguish the diffusion flame. The water droplets studied had a relatively broad size distribution (from 1 to $60 \mu \mathrm{m}$ ), with the number mean diameter of $15 \mu \mathrm{m}$ and Sauter mean diameter of $25 \mu \mathrm{m}$. With an increase in the velocity gradient, the flame approaches towards the stagnation plane and flame thickness decreases. The flame properties, such as flame location and flame thickness are insensitive to the water mass loading. Along the stagnation stream line, the velocity decreases towards a local minimum just before the flame front. In contrast, the velocity increases in the flame zone due to the thermal expansion, and then decreases towards the stagnation point. In the decelerating zone, the droplet mass flux decreases on approach to the flame zone due to a non-equilibrium in velocity of large droplets between liquid and gas phases. Furthermore, as the droplet-laden air approaches the flame front, the flow stream begins to diverge in the counterflow field. Since the small droplets move away from the burner axis, the divergence of the air flow acts to reduce the water droplet mass flux along the stagnation streamline. Large droplets moving faster than the air flow 'catch up' to slower ones just before the flame front, and the mass flux of the droplets tends to increase, resulting in the droplets accumulating just before the flame zone. Measurements of the velocities of individual droplets show that large droplets move faster than the small droplets which are in equilibrium (in velocity) between liquid and gas phases. Droplet behavior was found to be controlled by the Stokes number. Equilibrium in velocity is re-established just in front of the flame zone. Closer to the flame front, evaporation occurs and the mass flux of the droplets decreases drastically. On the other hand, thermophoresis acts on extremely small droplets to move them along the steep temperature gradient and these droplets are forced from the high to low temperature regions against the convection velocity. The thermophoretic velocity was estimated in the present study to be compared with the measured convection velocity and it was concluded that the thermophoretic effect is negligibly small over all sizes of droplets.
\end{abstract}

KEYWORDS: suppression, water droplet, extinguishment, counterflow diffusion flame, Stokes number, thermophoresis

\section{INTRODUCTION}

Since the production of halon compounds such as trifluorobromomethane $\left(\mathrm{CF}_{3} \mathrm{Br}\right.$, Halon 1301) was banned by the Montreal protocol, fine water droplets, ranging from 10 to $100 \mu \mathrm{m}$ in diameter, have been proposed to replace current fire protection agents which are no longer deemed environmentally acceptable. Water has favorable physical properties for fire suppression. Its high heat capacity and high latent heat of evaporation can absorb a significant quantity of heat from flames. Water also expands 1700 times when it evaporates to vapor, which results in the dilution of the surrounding oxygen concentration. With the formation of fine water droplets, the effectiveness of water droplets in fire suppression is increased, due to the significant increase in the surface area of water that is available for heat absorption and evaporation. Therefore, the primary mechanisms of extinguishment should be due to heat extraction and oxygen displacement, which lead to the theoretical considerations of water vapor/air dilution and kinetic effects at the molecular level [1]. 
A sprinkler is a typical conventional system which produces water droplets with diameters in the order of a millimeter [2,3]. A sprinkler system typically delivers a far greater volume of water than is required to suppress a given fire thermally, because large droplets pass through the flame zone without evaporating within the flame zone. The cooling capacity of large droplets is not completely utilized and a large amount of water remains as residue. However, the application of water in small droplets offers several advantages. Because smaller droplets have larger surface to volume ratios and longer suspension times in quiescent air, vaporization in the vicinity of the fire is greatly improved. Less water is therefore required to accomplish extinguishment of a fire, and liquid water residue is minimized. Small droplets also follow the flowfield of the combustion gases more closely, and thus have the capability of reaching obstructed area.

For coflowing diffusion flames, the relative contribution of thermal cooling and oxygen dilution to fire extinguishment has been studied and extinguishment was found to depend on the water droplet diameter, velocity and orientation of injection [4]. Because laminar diffusion flames, in practical fires, are strained to some extent, a practical diffusion flame should be more easily suppressed than strain-free flames as assumed in most computational analyses [5,6]. For co-flowing jets or cup burners, it was found that the "blow off" process is controlled by the behavior at the peak reactivity spot (i.e. reaction kernel), formed at the flame attachment point in the edge (base) of diffusion flame. The extinguishment of a coflowing jet flame is similar to premixed flame propagation in the reaction kernel, produced at the flame base. In contrast, it differs to a typical counterflow diffusion flame extinguishment as in this configuration the flame is extinguished by a blow off process rather than global extinguishment [7]. Nevertheless, it is interesting from a phenomenological perspective to study the extinguishment of strained diffusion flame without premixed reaction kernel by fine water droplets.

The counterflow configuration provides a convenient experimental configuration to understanding the interactions between droplets dynamics with flames, including flame extinguishment. Computational simulation, based on a hybrid Eulerian-Lagrangian formulation for gas and droplet phases, was performed for the analysis of effects of water droplets in extinguishing diffusion flames and the thermal effects, mainly through the latent heat of evaporation, were shown to significantly influence flame extinguishment [8-11]. The effect of thermal cooling and oxygen dilution on suppression of the large scale pool fires were reported qualitatively $[12,13]$.

In the counterflow diffusion flame configuration, droplets within a certain diameter range pass through the flame zone and remain in the liquid state. These droplets are then forced back by the opposing flow thus exhibiting an oscillatory motion in the vicinity of the stagnation plane. Water droplets with initial diameters smaller than the oscillatory threshold usually undergo complete evaporation upon entering the flame zone and therefore the effectiveness of flame extinguishment is deteriorated by increasing droplet diameters larger than a threshold diameter [14]. It has also been shown that there exists an optimal droplet diameter, beyond which the strain rate at extinguishment decreases linearly with increase in the specific surface area of the droplet. As the water droplets approach an optimal diameter, the linear correlation fails, suggesting an interaction between thermal and finite-rate reaction effects [8].

Using a counterflow propane-air flame, the behavior of droplets in the vicinity of the flame zone was investigated experimentally and it was found that $30 \mu \mathrm{m}$ is the threshold size of droplets above which droplets cannot evaporate completely within the flame zone [14]. The behavior of the droplets near the flame zone is rather complicated. Large droplets do not follow the flow of gas phase with high velocity gradient. In addition, the droplet threshold diameter is also affected by strain rate imposed by the flowfield, although it seems no systematic investigation has studied this effect. The dynamics of the droplets was analyzed numerically in the counterflow configuration [8], and large droplets undergo the oscillatory motion around the stagnation plane. The droplets of optimal size should evaporate in the oxygen consumption layer of the flame zone, which leads to the radical deactivation as well as thermal cooling [15].

Optimal use of water droplet systems requires detailed knowledge of the behavior and suppression effectiveness of water droplets in the vicinity of the flame as a function of droplet size as well as the flowfield. The details of the interaction between water droplets and flames have not yet been fully characterized. To understand the underlying physics of fire extinguishment of highly strained diffusion flame by fine water droplets, more experimental data is required, including measurement of the strain rate at extinguishment, and thermal and chemical effects of water droplets with various diameters and special distributions. In the present study, polydisperse water droplets are used, because poly-dispersion is essential 
for the practical water droplets generated by nozzles or ultrasonic water droplet generators.

\section{EXPERIMENTAL APPARATUS}

In the present study, water droplets are generated using a specially designed water droplet generator. Uniform air flow with water droplets is supplied from a wind tunnel. Downstream of the wind tunnel, a two-dimensional combustion chamber is used, in which a porous cylinder (made by sintered metal) was mounted to eject the fuel uniformly with low velocity. The counterflow diffusion flame is stabilized in the forward stagnation region of a porous cylinder. The characteristics of water droplets are measured by a phase Doppler particle analyzer (PDPA).

\section{Wind Tunnel and Combustion Chamber}

The experimental setup is shown in Fig. 1. Air is supplied from a blower to the water droplet generator and a controlled amount of the fine water droplets is added to the air flow. Details of the water droplet generator are given below. The air flow rate from the blower is adjusted by controlling the revolution of the driving motor and is measured using an appropriate orifice. The air stream with water droplets enters the wind tunnel which consists of a diffuser, a settling chamber and a converging nozzle of a contraction ratio of 17.4:1. The settling chamber with a cross section of $260 \mathrm{~mm} \times 260 \mathrm{~mm}$ and $330 \mathrm{~mm}$ in length contains three damping screens of 5,8 and 16 mesh, respectively. The combustion chamber is mounted vertically on the converging nozzle. The air stream entering the combustion chamber has a uniform velocity profile and the turbulence intensity is less than $2 \%$. The wind tunnel is mounted on the vertical-axis translation stage, so that the laser probe volume could be positioned anywhere along the stagnation stream line, to record droplet characteristics as a function of position.

The cross section of the rectangular combustion chamber is $30 \mathrm{~mm} \times 120 \mathrm{~mm}$ and an uncooled porous cylinder of $30 \mathrm{~mm}$ in diameter and $30 \mathrm{~mm}$ long is installed, the center being $110 \mathrm{~mm}$ downstream from the combustion chamber inlet. Both sides of the combustion chamber are fitted with $10 \mathrm{~mm}$ thick quartz windows to permit viewing and photographic observations and recording. The thickness of boundary layer developed on each window is less than $2 \mathrm{~mm}$ at the flame location and the flame is uniform except for these boundary layers. The downstream side of the cylinder surface is coated with heat-resisting paint in order to prevent ejection of fuel into the wake. The fuel used is methane (99.8\% pure) and its flow rate is controlled by a mass flow controller.

\section{Water Droplet Generator}

In the present study, high-purity water was used for producing water droplets. To generate fine water droplets, twin-fluid atomizers are used. Two twin-fluid atomizers are installed oppositely on both side walls

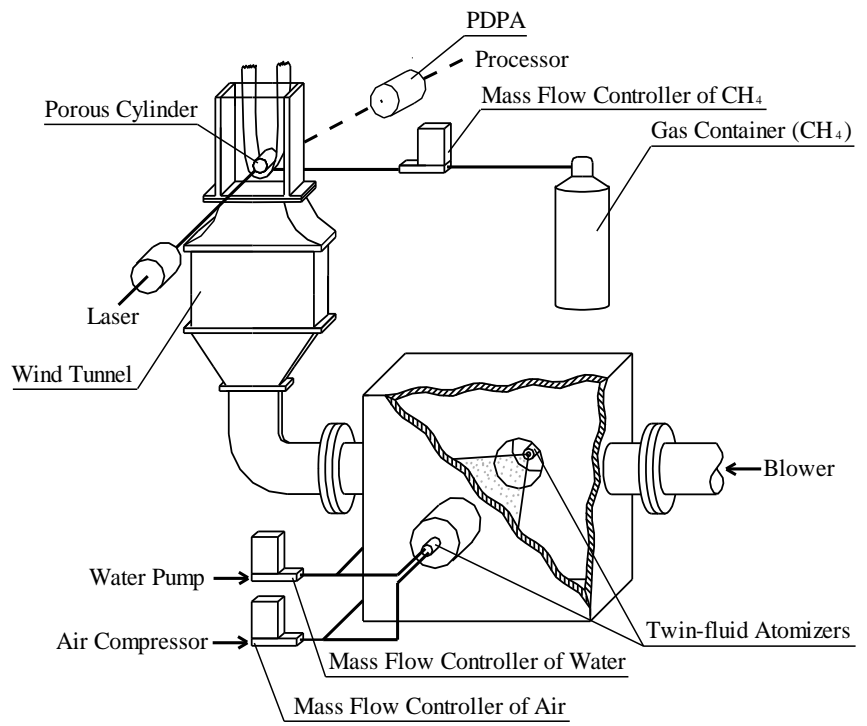

Fig. 1. Experimental apparatus. 
of the water droplet generator. Two sets of twin-fluid atomizers were used, of which nozzle diameters are $0.5 \mathrm{~mm}$ for AFAS (air fog atomizer, small) and $3.0 \mathrm{~mm}$ for AFAL (air fog atomizer, large), respectively. By operating one or both, the flow rate of water droplets can be varied over a wide range. The effect of coalescence of the colliding droplets was minimized by adjusting the distance of two atomizers which were oppositely placed. However, some effect of coalescence could remain within the limited space of the water droplet generator. Air and water flow rates supplied to atomizers were controlled by respective mass flow controllers. Water droplet diameters, their distributions and velocities were measured by a PDPA.

\section{EXPERIMENTAL RESULTS AND DISCUSSION}

\section{Counterflow Field and Flame Appearance}

Typical counterflow field produced in the forward stagnation region of a porous cylinder is shown in Fig. 2, where $V$ is the uniform air stream velocity, $v_{w}$ the fuel ejection velocity, $R$ the radius of cylinder, and $y^{*}$ the flame stand-off distance. The stagnation plane is formed between fuel and air streams. Under the assumption of fast chemistry, the flame would be established where the mass fluxes of fuel and oxidant are in stoichiometric proportions. Fuel and oxidant fluxes into the flame zone are from both diffusion and convection. In Fig. 2, the flame is on the oxidant side of the stagnation plane. To predict the direction of flame movement, we consider an increase in the convection velocity of the oxidant flow. This will cause an increase in the oxidant mass flux by convection into the flame zone. To satisfy reaction stoichiometry, the flow rate of the oxidant into the flame zone must decrease. This can be accomplished by movement of the flame towards the stagnation plane. The convective velocity of the oxidant at the flame would decrease because of the divergence of the streamline, and subsequently the oxidant mass flux into the flame zone would also decrease proportionately. The stoichiometric plane, and hence the flame would now be closer towards the stagnation plane. At the flame, therefore, the diffusive velocity $v_{d}$ is expressed by

$v_{d} \approx\left(\frac{d V}{d y}\right) y^{*}$.

As a result, the characteristic diffusive time $y^{*} / v_{d}$ is nearly proportional to inverse of the velocity gradient $\mathrm{d} V / \mathrm{d} y$, which coincides with the strain rate. With an increase in the velocity gradient, the flame moves closer towards the stagnation plane to accommodate the condition such that the mass fluxes of fuel and oxidant are in stoichiometric proportions. Since the flame location is determined by convective and diffusional processes, it may not be affected by the addition of water droplets.

A diffusion flame established in the forward stagnation region of a porous cylinder is characterized by the velocity gradient along the stagnation stream line, $2 V / R$, and the non-dimensional ejection parameter, $-f_{w}=$ $\left(v_{w} / V\right)(R e / 2)^{1 / 2}$, where $R e$ is the Reynolds number based on the air velocity and the cylinder radius.

When $V$ is very small and $v_{w}$ is comparatively large, the flame shows luminous yellow inner (fuel side) and blue outer (air side) zones, and the flame thickness is remarkably large. Figure 3 shows a typical example of such flame for $2 V / R=68 \mathrm{~s}^{-1}$ and $-f_{w}=5.35$. In the limiting case of small $V$, the luminous yellow flame and the blue flame are separated completely, and the narrow dark zone appears between these separated

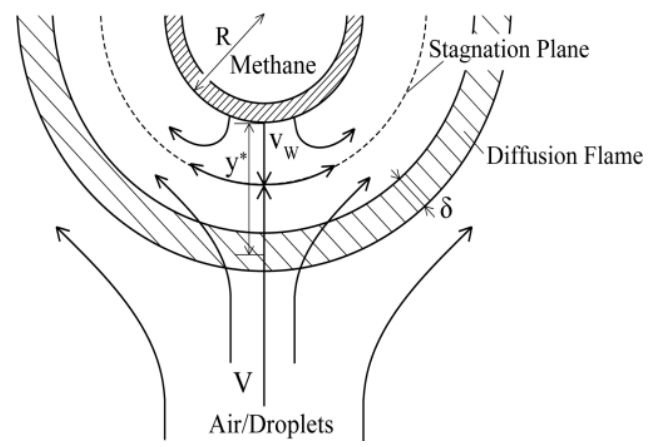

Fig. 2. Counterflow field. 


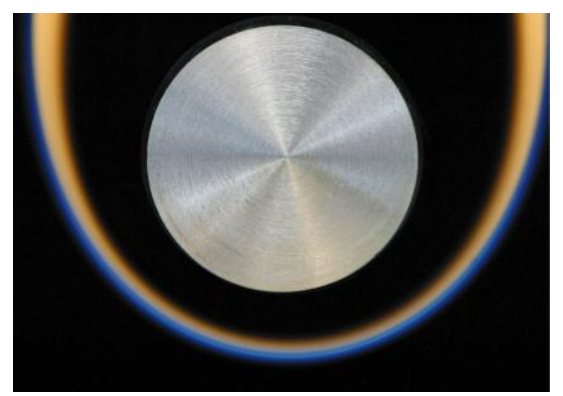

Fig. 3. Counterflow diffusion flame for $2 V / R=68 \mathrm{~s}^{-1}$ and $-f_{w}=5.35$.

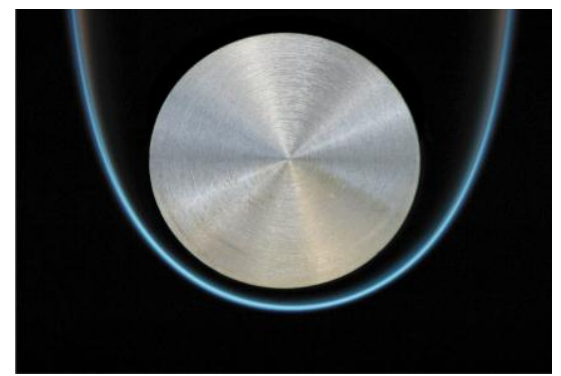

Fig. 4. Counterflow diffusion flame for $2 V / R=300 \mathrm{~s}^{-1}$ and $-f_{w}=2.49$.

flames. With an increase in $V$ and for an appropriate $v_{w}$, the flame thickness decreases significantly and a thin, laminar, two-dimensional blue flame is stabilized at some distance from the cylinder surface. The counterflow diffusion flame in this region is shown in Fig. 4 for $2 V / R=300 \mathrm{~s}^{-1}$ and $-f_{w}=2.49$. This flame was very stable and simple in configuration. The fuel pyrolysis intermediates and the reaction routes leading to soot formation play an important role in producing the yellow flame. The soot production rate increases with the fluid element residence time in the high temperature pyrolysis zone of the flame. For the case of $2 V / R=68 \mathrm{~s}^{-1}$ and $-f_{w}=5.35$, with the increase in flame thickness, the residence time is much longer than for $2 V / R=300 \mathrm{~s}^{-1}$ and $-f_{w}=2.49$ due to small velocity gradient.

As $v_{w}$ is decreased or $V$ is increased, the flame approaches the cylinder surface, and finally flame extinguishment occurs at the stagnation region and the flame is suddenly converted into the so-called wake flame. This extinguishment of the flame occurs very abruptly at flow rates reproducible to within $3 \%$. It is clear that the blue flame is on the oxidant side of the stagnation plane. For the counterflow diffusion flame, fuel mass flux is balanced with oxidant mass flux in stoichiometric proportions under the assumption of fast chemistry. Therefore, with decrease in $v_{w}$ or increase in $V$, the flame is established closer to the stagnation plane. Actually, the chemical reaction rate is finite, and the flame extinguishment occurs due to the incomplete combustion.

When $V$ is very large, the flame cannot be stabilized in the forward stagnation region, even if the fuelejection velocity is large enough, and it is found that there exists a critical stagnation velocity gradient, $(2 V / R)_{c}$, beyond which the flame can never be stabilized. Here, it should be noted that the velocity gradient coincides with the strain rate acting on the flame surface for the counterflow configuration. The limit of extinguishment obtained in the present study without water droplets is $423 \mathrm{~s}^{-1}$ as compared to the theoretical value of $460 \mathrm{~s}^{-1}[16,17]$.

When fine water droplets are added, both the yellow zone and the blue flame became dark for low strain case, while for high strain cases, blue flame became dark. The rate of soot production depends on the rate of surface growth and the rate of formation of soot precursor produced during fuel pyrolysis [18]. The latter process is more sensitive to oxygen concentration and flame temperature. If we assume that the fine water droplets supplied evaporate completely in the flame zone $(51.5 \mathrm{ml} / \mathrm{min}$, highest case in the present study), the oxygen concentration decreases to $18.8 \%$ and the adiabatic flame temperature decreases by $400 \mathrm{~K}$ for $2 V / R=68 \mathrm{~s}^{-1}$, which leads to a significant decrease in the soot formation. 
A chemical effect of the fine water droplets is also expected and is attributed to the reaction of gaseous fuel with water vapor, which should be decoupled from the thermal effect associated with evaporation of

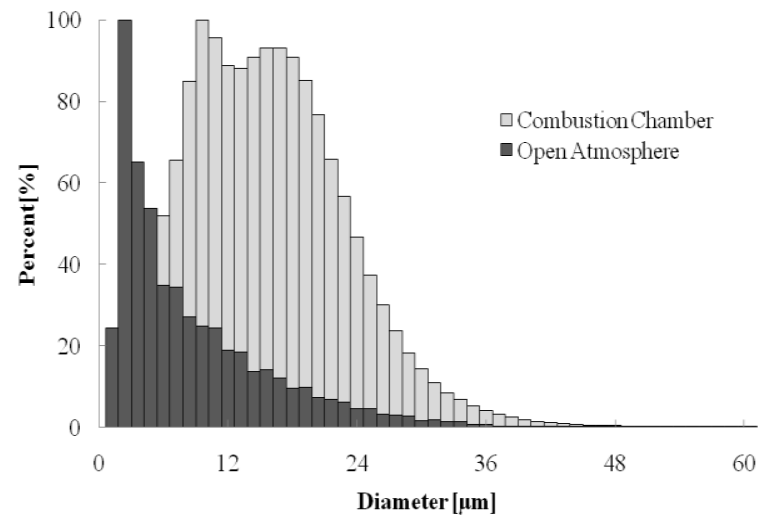

Fig. 5. Size distributions in open atmosphere and in combustion chamber.

droplets. It was found that water vapor inhibits the soot formation and shifts $\mathrm{CO}$ to $\mathrm{CO}_{2}$ through water gas reaction, $\mathrm{CO}+\mathrm{H}_{2} \mathrm{O}=\mathrm{CO}_{2}+\mathrm{H}_{2}$, when introducing water vapor at the base of the pool flame [19].

\section{Water Droplet Characteristics}

The droplet size distributions measured in the open atmosphere, at $60 \mathrm{~mm}$ downstream from the inlet of the combustion chamber is shown in Fig. 5 in which the vertical axis shows the number of droplets within each bin normalized by the maximum number in a particular bin. Air and water flow rates supplied to an atomizer are $50 \mathrm{l} / \mathrm{min}$ and $37.5 \mathrm{ml} / \mathrm{min}$, respectively. The droplet size distribution measured in the open atmosphere is close to the Rosin-Rammler distribution as compared with a log-normal distribution as in Refs. $[8,20]$. However, the distribution measured in the combustion chamber is nearly normal, and in some cases two peaks appear in the size distribution. This difference can be attributed to the coalescence of the colliding droplets and also to the fact that a part of droplets are trapped in the passage of droplet-laden air flow.

The water mass flow rate supplied to the twin-fluid atomizers, $Q_{w 0}$, was compared with that measured at the flame location, $Q_{w}$, and it was found only about $40-70 \%$ of the mass of water supplied to the atomizers reached the flame location. Remainder, especially small droplets, was trapped by damping screens in the settling chamber or deposited on the wind tunnel walls. As a result, the droplet size distribution was distorted from the original Rosin-Rammler distribution. The operation of the droplet generation system was very consistent over the entire range of water and air flows of tests. For $Q_{w 0}$ at extinguishment in this study, the number mean diameter, $D_{10}$ ranged from 15 to $20 \mu \mathrm{m}$ and the Sauter mean diameter, $D_{32}$ ranged from 25 to $30 \mu \mathrm{m}$ and are slightly larger than those used in [7].

\section{Flame Location and Flame Thickness}

Figure 6 shows the flame location as a function of the velocity gradient. It is clear that the flame moves closer towards the stagnation plane with an increase in the velocity gradient. However, the flame location is independent of the water droplet mass loading, which suggests that the water droplets don't affect the diffusion of fuel or the convection of oxidant.

Figure 7 shows the flame thickness as a function of the velocity gradient. The flame zone is defined here as the region of which temperature is above $1400 \mathrm{~K}$. The flame thickness decreases with an increase in the velocity gradient, and is independent of the water droplet mass loading.

The flame properties, such as flame location and flame thickness are determined by the diffusion of methane and the convection of oxidant in the counterflow configuration. Water droplets influence the chemical reactions through cooling and oxygen depletion by evaporation, but the flame properties such as flame location and flame thickness are determined essentially by physical processes, such as diffusion and convection, and are not strongly affected by the water droplet addition. 


\section{Flame Structure and Droplet Behavior}

The thermal effects of droplets on flame structure are reflected in the temperature distributions. In the present study, a silica-coated thermocouple wire of diameter of $50 \mu \mathrm{m}$ was used for temperature measurements. Radiation losses from the thermocouple junction were corrected for at each measured temperature [21]. Strictly speaking, the measured temperature does not coincide with the gas temperature due to the presence of water droplets. However, the error was confirmed to be negligible $(<2 \%)$ by a simple analysis.

Figures 8 to 10 show the temperature distributions along the stagnation stream line for $Q_{w}=0,32.4$ and $51.5 \mathrm{ml} / \mathrm{min}$, respectively. With an increase in the velocity gradient, the flame moves closer towards the stagnation plane. At the same time, the flame thickness decreases and the temperature gradient at the flame front becomes steeper. The maximum temperature reduces with the increasing velocity gradient and also with water droplets mass loading. A decrease in the maximum flame temperature with increasing velocity gradient was predicted from numerical simulations and it should be noted that the maximum flame temperature at extinguishment without water droplets is roughly $200 \mathrm{~K}$ lower in comparison with the predicted value [17]. Based on these figures, it is clear that the flame location and thickness do not change significantly on the addition of water droplets.

With an increase in the velocity gradient, the diffusive flux of methane to the flame zone increases in accordance with the stoichiometric reaction between methane and the oxidant. In reality, the reaction rate is finite and a portion of methane doesn't react with oxidant. The unreacted methane reduces the maximum temperature as the velocity gradient is increased. Since water droplets extract heat from the flame due to evaporation, the temperature is reduced upon water droplet addition.

Figure 11 shows the profiles of velocity, water droplet mass flux and number mean diameter of droplets along the stagnation stream line for $2 V / R=68 \mathrm{~s}^{-1},-f_{w}=5.35$ and water droplets flow rate, $Q_{w}$, of $32.4 \mathrm{ml} / \mathrm{min}$. Generally it can be seen that the approach flow is first significantly decelerated well before the flame front. It decreases with a near-linear slope to the air side flame edge, just before reaching a local minimum. This slope, used to define the strain rate, coincides with the divergence of the oxidant flow. Closer to the flame front, a dramatic acceleration is observed, due to thermal expansion. The free stream

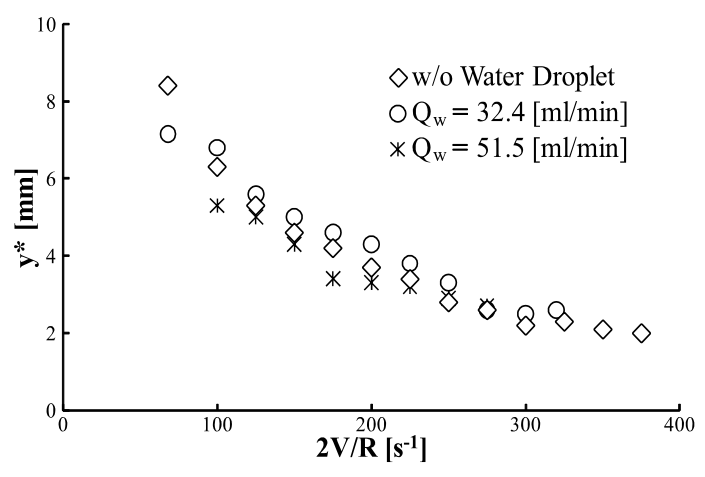

Fig. 6 Flame location.

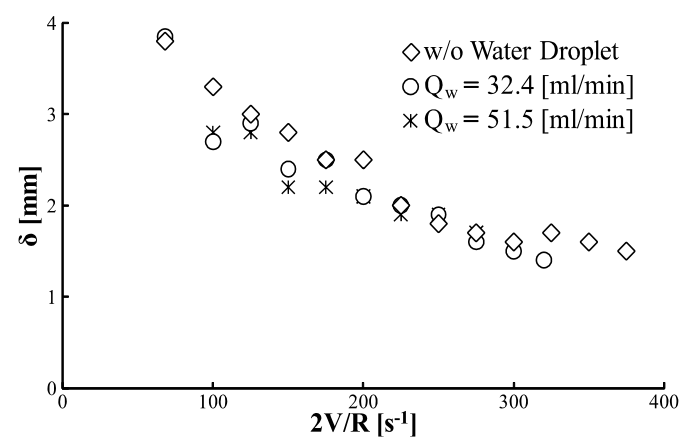

Fig. 7 Flame thickness. 


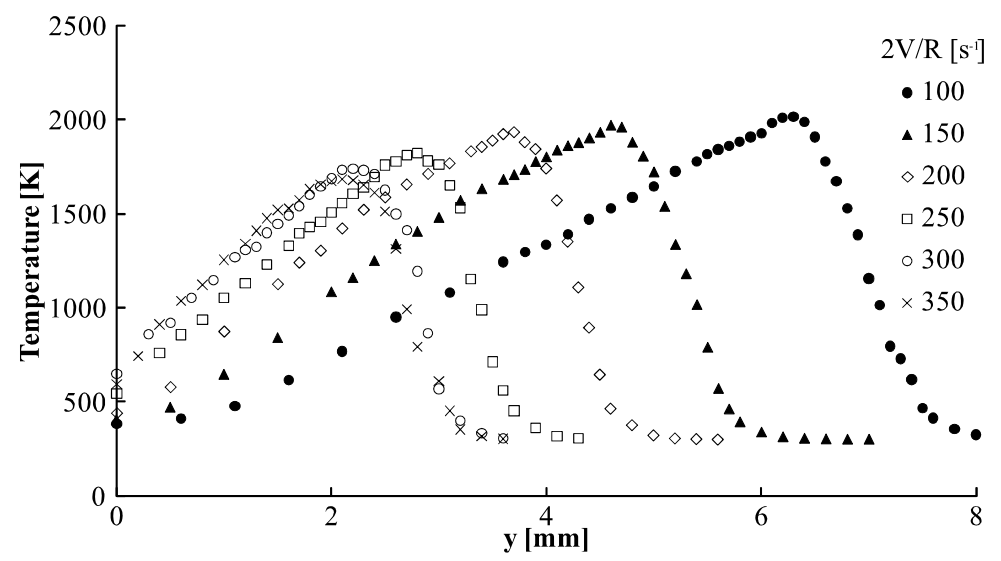

Fig. 8. Temperature distributions without water droplets.

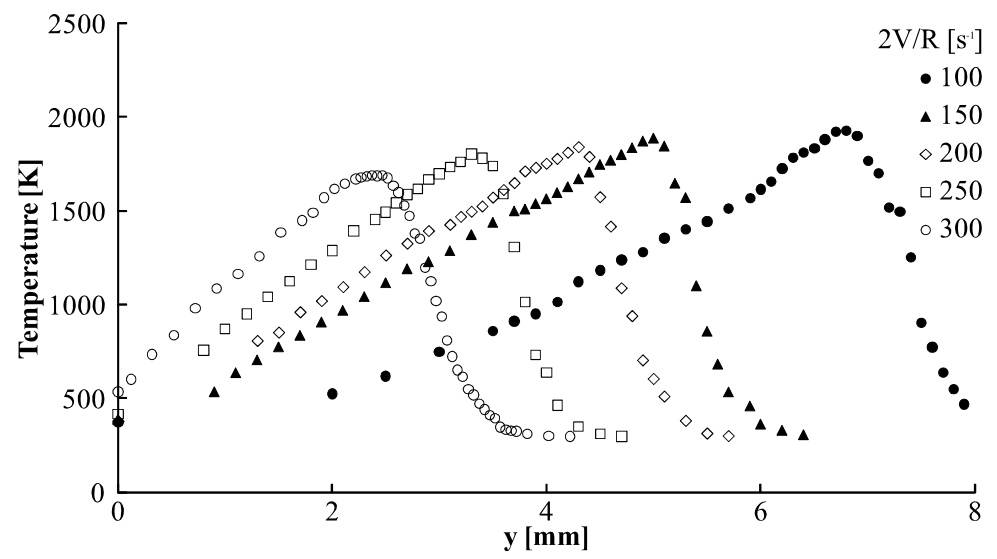

Fig. 9. Temperature distributions for $Q_{w}=32.4 \mathrm{ml} / \mathrm{min}$.

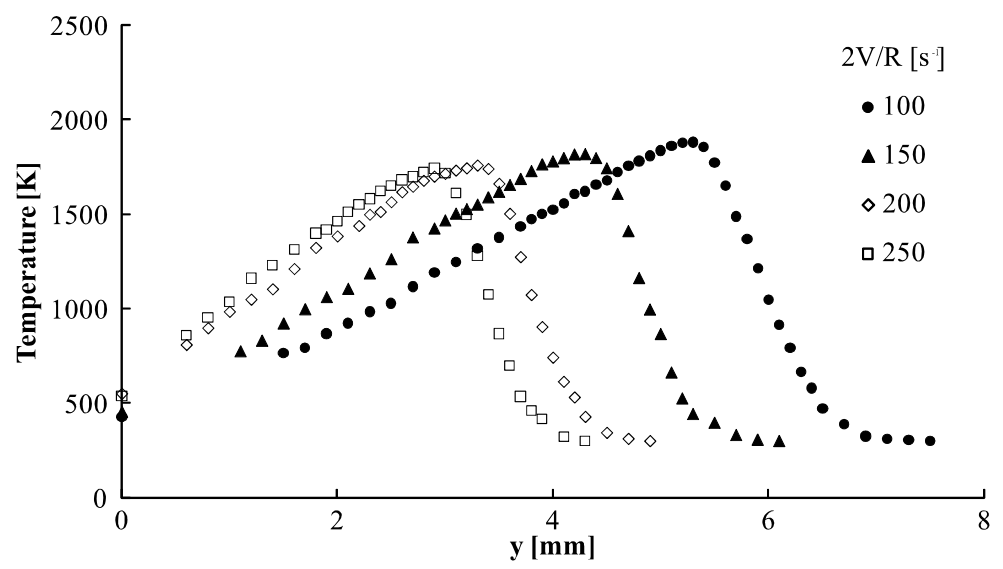

Fig. 10. Temperature distributions for $Q_{w}=51.5 \mathrm{ml} / \mathrm{min}$.

approach flow velocity was $0.51 \mathrm{~m} / \mathrm{s}$ and resulted in a velocity gradient $2 V / R$ of $68 \mathrm{~s}^{-1}$, which satisfies conditions for the production of soot in the flame. Maximum velocity in the flame zone was $0.35 \mathrm{~m} / \mathrm{s}$.

The mass flux of droplets decreases slightly along the stagnation stream line. In the regions where the droplets are decelerating, large droplets move faster than the small droplets, because the inertial force is large compared to the effect of viscous drag. Furthermore, when approaching the stagnation point, the flow streamlines begin to diverge in the counterflow field, and the small droplets move away from the burner 


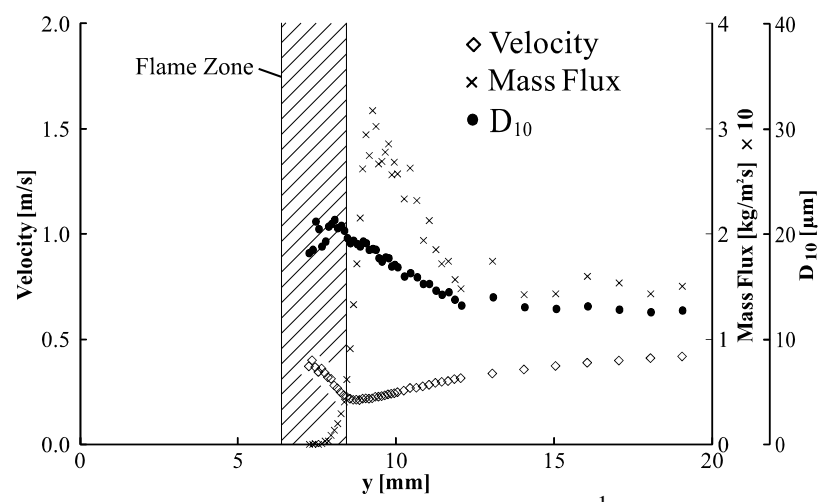

Fig. 11. Velocity, $D_{10}$ and mass flux profiles for $2 V / R=68 \mathrm{~s}^{-1},-f_{w}=5.35$ and $Q_{w}=32.4 \mathrm{ml} / \mathrm{min}$.

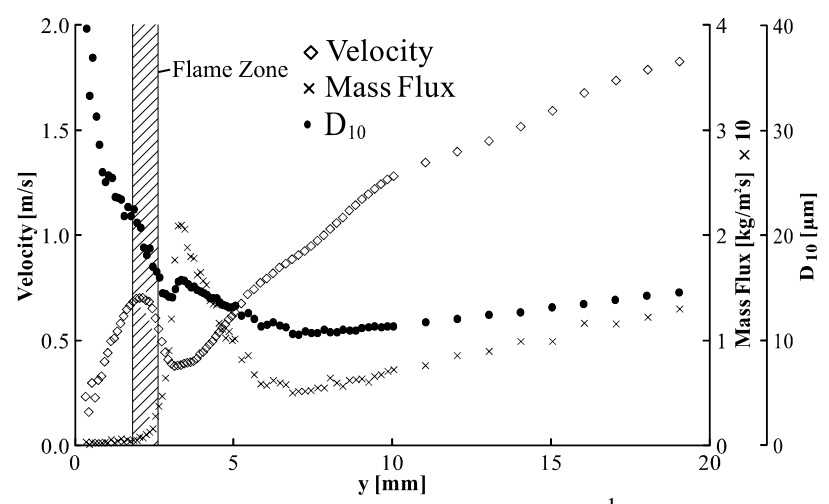

Fig. 12. Velocity, $D_{10}$ and mass flux profiles for $2 V / R=300 \mathrm{~s}^{-1},-f_{w}=2.49$ and $Q_{w}=32.4 \mathrm{ml} / \mathrm{min}$.

axis. As a result, the droplet mass flux decreases whereas the number mean diameter increases with approaching the flame zone.

The mass flux of droplets increases just before the flame zone. In the near flame region, faster moving droplets "catch up" to the slower ones and drag forces act to re-establish an equilibrium in velocity between liquid and gas phases. Closer to the flame front, the fine water droplets evaporate and the mass flux summed over all size ranges decreases. In this case, virtually no droplets of any size are detected in the flame zone, highlighting that all the droplets undergo essentially complete vaporization when they enter the reaction zone. This suggests that the lifetime of the droplets with a wide range of size distribution are shorter than their residence time in the flame zone. The number mean diameter increases with approaching the flame zone due to fast evaporation of small droplets. The remaining large droplets also evaporate in the vicinity of the flame zone, and the number mean diameter decreases slightly in the flame zone.

Figure 12 shows the profiles of velocity, water droplet mass flux and number mean diameter of droplets along the stagnation stream line for $2 V / R=300 \mathrm{~s}^{-1},-f_{w}=2.49$ and water droplets flow rate, $Q_{w}$, of 32.4 $\mathrm{ml} / \mathrm{min}$. The velocity initially drops with the constant slope as the gases move towards the stagnation plane then it increases as the hot gases expand in the reaction zone. Finally the flow slows down towards the stagnation point. The free stream approach flow velocity was $2.25 \mathrm{~m} / \mathrm{s}$ and resulted in a velocity gradient $2 V / R$ of $300 \mathrm{~s}^{-1}$, which satisfies conditions for the blue flame without the luminous yellow zone. Maximum velocity in the flame zone was $0.70 \mathrm{~m} / \mathrm{s}$.

The water droplet mass flux decreases with approaching the flame zone due to the fact that insufficiently decelerated large droplets move faster than small ones which move strictly with gas phase without any slip. Closer to the flame front, the droplet mass flux increases due to the re-establishment of equilibrium in velocity between the liquid and gas phases. The water droplet mass flux decreases drastically in passing through the flame zone due to the rapid evaporation of droplets and also to the flow divergence. The droplets that are detected in or beyond the flame zone have a much larger mean size than do the incident droplets due to the rapid evaporation of the small droplets. As compared with Fig. 11, there should be a 


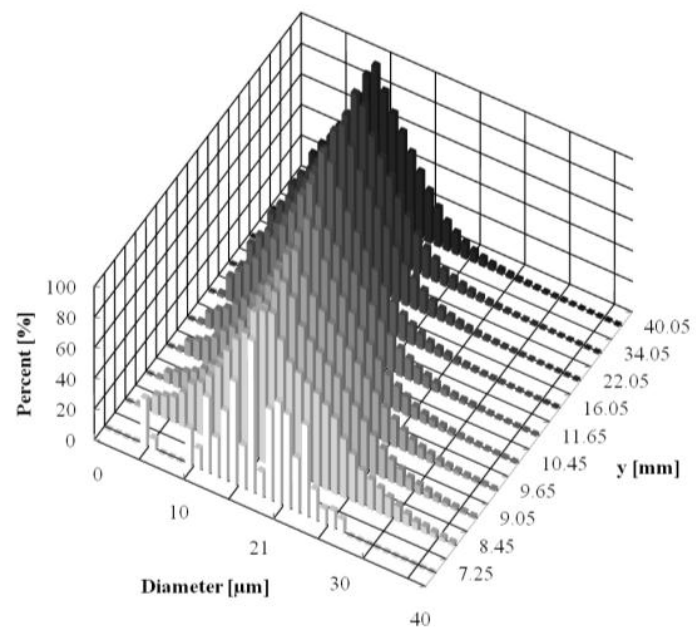

Fig. 13. Size distributions of droplets along stagnation stream line for $2 V / R=68 \mathrm{~s}^{-1}$ and $Q_{w}=32.4 \mathrm{ml} / \mathrm{min}$.

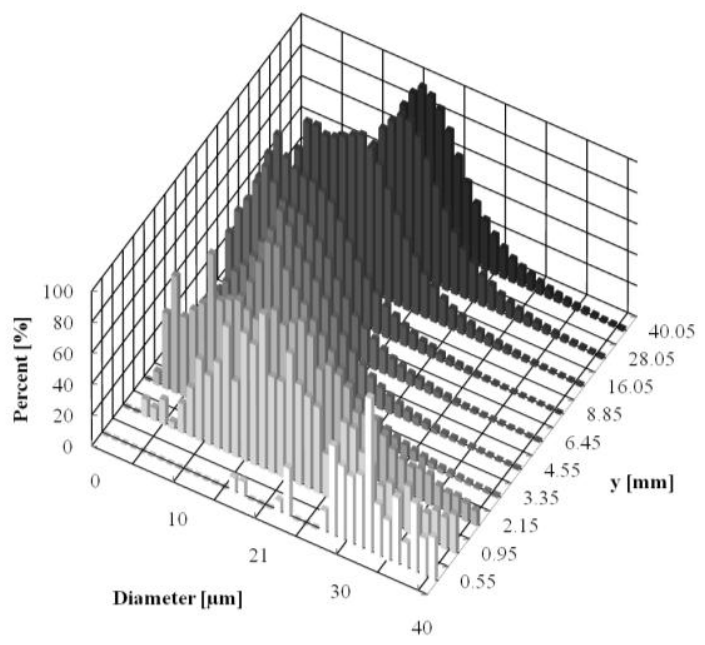

Fig. 14. Size distributions of droplets along stagnation stream line for $2 V / R=300 \mathrm{~s}^{-1}$ and $Q_{w}=32.4 \mathrm{ml} / \mathrm{min}$.

minimum size capable of penetrating the flame zone and will be determined by the size distribution, the lifetime of the droplets of each size and the residence time in the high temperature region.

Figure 13 shows the droplet size distributions as a function of the position $(y)$ measured from the burner surface for the case of $2 V / R=68 \mathrm{~s} \mathrm{~s}^{-1},-f_{w}=5.35$ and $Q_{w}=32.4 \mathrm{ml} / \mathrm{min}$. The size distribution far upstream of the flame zone ranges from 1 to $40 \mu \mathrm{m}$. When approaching the flame zone, the peak moves towards the larger size due to the accumulation of large droplets which move faster than small ones just before the flame zone. The number mean diameter increases because small droplets move away from the stagnation stream line due to the flow divergence. Closer to the flame front, evaporation of droplets occurs and the number mean diameter decreases drastically. Virtually none of the droplets of any size are detected once the flame is reached.

Figure 14 shows the droplet size distributions as a function of the position $(y)$ measured from the burner surface for the case of $2 V / R=300 \mathrm{~s}^{-1},-f_{w}=2.49$ and $Q_{w}=32.4 \mathrm{ml} / \mathrm{min}$. The size distribution far upstream of the flame zone is same as the case of $2 V / R=68 \mathrm{~s}^{-1}$. Since in the decelerating input flow, the large droplets move faster than the small ones due to the non-equilibrium in velocity, the probability of appearance of larger droplets decreases, and the number mean diameter also decreases. On approaching the flame zone, the equilibrium in velocity is re-established and the faster droplets "catch up" to slower ones and accumulation of large droplets occurs close to the flame front.

When passing through the flame zone, the probability of a small size decreases which reflects the rapid evaporation of the small droplets as well as the flow divergence. At the inner (fuel side), with a drastic 
decrease in the droplet mass flux, the relatively large droplets remain which are not evaporated in the flame zone. In the flame zone, the peak shifts towards the larger size, suggesting again the rapid evaporation of small droplets. The droplets that are detected in or beyond the flame zone have a broad size distribution and a much larger number mean diameter than do the droplets in the approach flow. The droplet lifetime should be longer than the residence time for this case. These observations indicate that for $2 V / R=68 \mathrm{~s}^{-1}$, all the droplets undergo essentially complete evaporation once they enter the reaction zone, while for $2 V / R=300$ $\mathrm{s}^{-1}$, large droplets pass through the flame zone. For $Q_{w}=32.4 \mathrm{ml} / \mathrm{min}$, the extinguishment occurs at $2 V / R=$ $340 \mathrm{~s}^{-1}$ and the threshold size below which droplets are completely evaporated becomes smaller, because the residence time reduces with the stagnation velocity gradient. It should be noted that the minimum size capable of penetrating the flame zone is affected by the velocity gradient.

\section{Droplet Dynamics}

The droplet response to the variation in gas phase flow conditions can be characterized by the Stokes number, St. By defining the flow residence time as $t_{f}=R / 2 \mathrm{~V}$, and the droplet response time, based on Stokes drag, as $t_{d}=\rho_{w} D_{0}{ }^{2} / 18 \mu$, where $\rho_{w}$ and $D_{0}$ are density and diameter of droplet and $\mu$ viscosity of air, $S t$ is expressed by Eq. 2 .

$S t=\frac{t_{d}}{t_{f}}=\left(\frac{\rho_{w} D_{0}^{2}}{18 \mu}\right)\left(\frac{2 V}{R}\right)$

For the strain rates of $68 \mathrm{~s}^{-1}$ and $300 \mathrm{~s}^{-1}$ considered in the present study, the variation of $S t$ for different sizes of droplets added in the air flow is shown in Table 1. It is seen that for the case of $2 V / R=68 \mathrm{~s}^{-1}, S t$ is smaller than 1 for droplets with all sizes considered $(<60 \mu \mathrm{m})$, and all the droplets seem to follow the gas flow. However, for the case of $2 V / R=300 \mathrm{~s}^{-1}$, as the droplet size approaches $35 \mu \mathrm{m}$, St exceeds 1 , indicating that the response of the droplets larger than $35 \mu \mathrm{m}$ is much slower.

Figure 15 shows the velocities of droplets of each size for $2 V / R=68 \mathrm{~s}^{-1}$. Far upstream of the flame front, $y$ $=21.05 \mathrm{~mm}$, droplets smaller than $40 \mu \mathrm{m}$ follow the decelerating flow field. Droplets larger than $40 \mu \mathrm{m}$ move faster than the small droplets and these large droplets are accumulated in front of the flame zone. Closer to the flame front, $y=9.25 \mathrm{~mm}$, the equilibrium in velocity is re-established and all the droplets have an equal velocity.

The velocities of droplets of each size for $2 V / R=300 \mathrm{~s}^{-1}$ is shown in Fig. 16. Upstream of the flame zone, $y$ $=5.25 \mathrm{~mm}$, the droplet velocity increases with the droplet diameter, which means the insufficient deceleration of large droplet due to the large inertial force compared to the drag force. Droplet mass flux decreases in the decelerating stagnation flow because the droplet outflow to downstream out of the control volume exceeds the inflow into it from upstream. Furthermore, flow divergence induces the loss of small droplets which move away from burner axis due to flow divergence. Closer to the flame front, $y=3.25 \mathrm{~mm}$ and $2.85 \mathrm{~mm}$, since the deceleration is mitigated, the equilibrium in velocity tends to be re-established and

Table 1. Stokes number.

\begin{tabular}{|r|c|c|}
\hline$D_{0}(\mu \mathrm{m})$ & $2 V / R=68\left(\mathrm{~s}^{-1}\right)$ & $2 V / R=300\left(\mathrm{~s}^{-1}\right)$ \\
\hline 5 & 0.0051 & 0.0223 \\
10 & 0.0202 & 0.0892 \\
15 & 0.0455 & 0.2007 \\
20 & 0.0808 & 0.3567 \\
25 & 0.1264 & 0.5577 \\
30 & 0.1819 & 0.8028 \\
35 & 0.2477 & 1.0929 \\
40 & 0.3235 & 1.4274 \\
45 & 0.4094 & 1.8066 \\
50 & 0.5054 & 2.2302 \\
55 & 0.6115 & 2.6985 \\
60 & 0.7281 & 3.2130 \\
\hline
\end{tabular}


droplets smaller than $40 \mu \mathrm{m}$ have an equal velocity, although the droplets larger than $40 \mu \mathrm{m}$ are not decelerated sufficiently and penetrate into the flame zone. Droplet mass flux in the near-flame region decreases drastically due to the rapid evaporation of small droplets.

Stokes numbers of respective droplets are also plotted in Figs. 15 and 16. For $2 V / R=68 \mathrm{~s}^{-1}$, Fig. 15, the Stokes number is smaller than 1 for all sizes of droplets. However, a slight non-equilibrium in velocity is found for the droplet sizes larger than $40 \mu \mathrm{m}$. For $2 V / R=300 \mathrm{~s}^{-1}$, Fig. 16, a non-equilibrium in velocity is found in the decelerating stagnation flow even if the Stokes number is as small as 0.1. In the re-establishing region of the droplet velocities, where the velocity gradient is reduced in front of the flame zone, droplets up to $35 \mu \mathrm{m}$ have an equal velocity, which corresponds to the unity Stokes number. Therefore, except for the region with steep velocity gradient, unity Stokes number is the best criterion for the equilibrium in velocity.

For the extremely small droplets, the thermophoresis is the important factor to control the droplet behavior. When the Knudsen number is as small as the present case, the thermophoretic velocity $V_{t}$ is expressed by

$V_{t}=-\frac{3 v}{2 T_{m}}\left(\frac{1}{1+6 l / D}\right)\left(\frac{\lambda_{g} / \lambda_{p}+4.4 l / D}{1+2 \lambda_{g} / \lambda_{p}+8.8 l / D}\right) \frac{d T}{d y}$,

where $v$ is kinematic viscosity of air, $T_{m}$ mean temperature, $l$ mean free path of air, $\lambda_{g}$ heat conductivity of air, $\lambda_{p}$ heat conductivity of water, $D$ diameter of a droplet, and $\mathrm{d} T / \mathrm{d} y$ temperature gradient [22]. The thermophoretic velocities of respective droplets are also plotted in Figs. 15 and 16. The thermophoretic

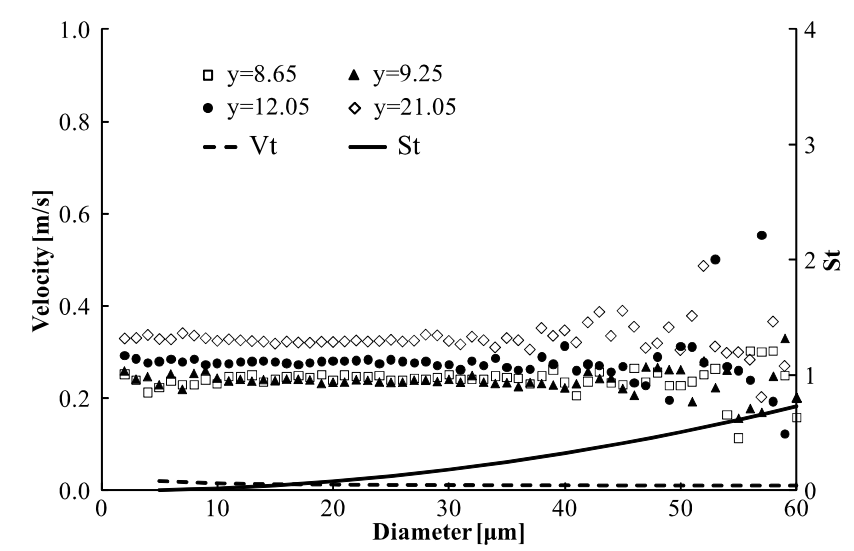

Fig. 15. Droplet velocities, Stokes numbers and thermophoretic velocities for $2 V / R=68 \mathrm{~s}^{-1}$ and $Q_{w}=32.4 \mathrm{ml} / \mathrm{min}$.

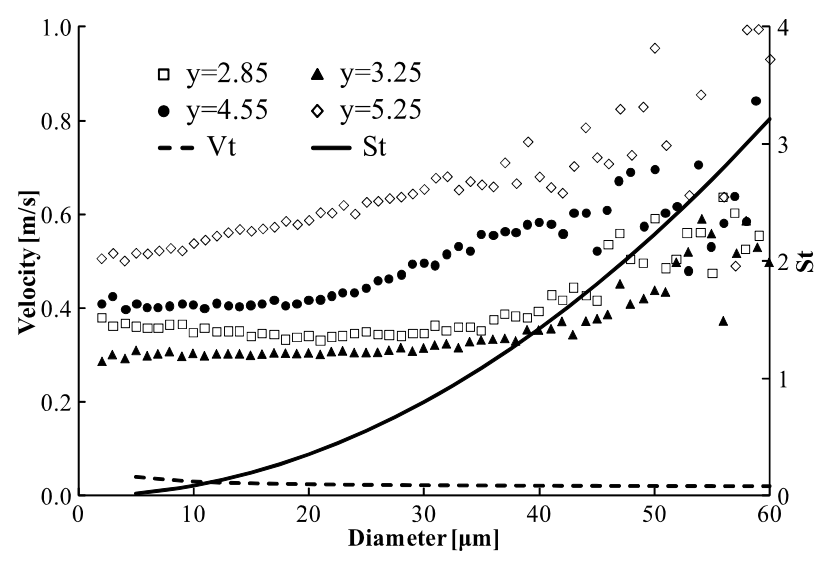

Fig. 16. Droplet velocities, Stokes numbers and thermophoretic velocities for $2 V / R=300 \mathrm{~s}^{-1}$ and $Q_{w}=32.4 \mathrm{ml} / \mathrm{min}$. 
velocities for $2 V / R=68 \mathrm{~s}^{-1}$ are $-0.013 \mathrm{~m} / \mathrm{s}$ and $-0.025 \mathrm{~m} / \mathrm{s}$ for $2 V / R=300 \mathrm{~s}^{-1}$, and the dependence on the droplet diameter is almost negligible. These velocities are much smaller as compared to the convection velocity.

\section{CONCLUSIONS}

In the present study, the behavior of fine water droplets, when applied to extinguishment of a flame, was investigated using methane-air counterflow diffusion flame. Droplet characteristics were measured by phase Doppler particle analyzer (PDPA) and temperature measurements were performed using a silicacoated fine thermocouple. The diameter of water droplets used in the present study ranges from 1 to $60 \mu \mathrm{m}$, the number mean diameter being from 15 to $20 \mu \mathrm{m}$ and the Sauter mean diameter from 25 to $30 \mu \mathrm{m}$. With an increase in the velocity gradient, the flame approaches the stagnation plane and flame thickness decreases. The flame properties, such as flame location and flame thickness are insensitive to the water mass loading. Along the stagnation stream line, the velocity decreases towards a local minimum just before the flame front. It increases in the flame zone due to the thermal expansion, and then decreases towards the stagnation point. In the decelerating zone, the droplet mass flux decreases on approach to the flame zone due to the non-equilibrium in velocity of large droplets between liquid and gas phases. Furthermore, as the droplet-laden air approaches the flame front, the flow stream begins to diverge in the counterflow field. Since the small droplets move away from the burner axis, the divergence of the air flow acts to reduce the water droplet mass flux along the stagnation streamline. Large droplets moving faster than the air flow "catch up" to slower ones just before the flame front, and the mass flux of the droplets will tend to increase, resulting in the droplets accumulation just before the flame zone. Measurements of velocities of individual droplets show that the large droplets move faster than the small droplets which are in equilibrium in velocity between liquid and gas phases. Droplet behavior was found to be controlled by the Stokes number. An equilibrium in velocity is re-established just in front of the flame zone. Closer to the flame front, evaporation occurs and the mass flux of the droplets decreases drastically. On the other hand, the thermophoresis acts on extremely small droplet to move them along the steep temperature gradient and extremely small droplets are forced from the high to low temperature regions against the convection velocity. However, the thermophoretic velocities estimated in the present study to be compared with the measured convection velocity were negligibly small over all sizes of droplets.

\section{REFERENCES}

[1] Mawhinney, J.R., Dlugogorski, B.Z. and Kim, A.K., 1994. A Closer Look at the Fire Extinguishing Properties of Water Mist. Fire Safety Science 4: 47-60. http://dx.doi.org/10.3801/IAFSS.FSS.4-47

[2] Grant, G., Brenton, J., and Drysdale, D., (2000) Fire Suppression by Water Sprays, Prog. Energy Combust. Sci. 26:79-130, http://dx.doi.org/10.1016/S0360-1285(99)0012-X

[3] Wu, D., Guillemin, D., and Marshall, A.W., (2007) A Modeling Basis for Predicting the Initial Sprinkler Spray, Fire Safety Journal 42:283-294, http://dx.doi.org/10.1016/j.firesaf.2006.11.007

[4] Prasad, K., Li, C., and Kailasanath, K., (1998) Optimizing Water-Mist Injection Characteristics for Suppression of Coflow Diffusion Flames, Proc. Combust. Inst. 27: 2847-2855.

[5] Yang, W. and Kee, R.J., (2002) The Effect of Monodisperse Water Mists on the Structure, Burning Velocity, and Extinction Behavior of Freely Propagating, Stoichiometric, Premixed, Methane-Air Flames, Combust. Flame 130:322-335, http://dx.doi.org/10.1016/s0010$\underline{2180(2) 00382-6}$

[6] Modak, A.U., Abbud-Madrid, A., Delplanque, J.-P., and Kee, R.J., (2006) The Effect of MonoDisperse Water Mist on the Suppression of Laminar Premixed Hydrogen-, Methane-, and Propane-Air Flames, Combust. Flame 144:103-111, http://dx.doi.org/10.1016/j.combustflame. $\underline{2006.07 .003}$

[7] Takahashi, F. and Katta, V.R., (2009) Extinguishment of Diffusion Flames around a Cylinder in a Coaxial Air Stream with Dilution or Water Mist, Proc. Combust. Inst. 32:2615-2623, http:// dx.doi.org/10.1016/j.proci.2008.05.028 
[8] Lentati, A.M. and Chelliah, H.K., (1998) Dynamics of Water Droplets in a Counterflow Field and Their Effect on Flame Extinction, Combust. Flame 115:158-179., http://dx.doi.org/10.1016/ $\underline{\text { S0010-2180(97)00355-6 }}$

[9] Lentati, A.M. and Chelliah, H.K., (1998) Physical, Thermal, and Chemical Effects of Fine-Water Droplets in Extinguishing Counterflow Diffusion Flames, Proc. Combust. Inst. 27:2839-2846.

[10] Lazzarini, A.K., Krauss, H., Chelliah, H.K., and Linteris, G.T., (2000) Extinction Conditions of Non-Premixed Flames with Fine Droplets of Water and Water/NaOH Solutions, Proc. Combust. Inst. 28:2939-2945, http://dx.doi.org/10.1016/S0082-0784(00)80719-5

[11] Chelliah, H.K., Lazzarini, A.K., Wanigarathne, P.C., and Linteris, G.T., (2002) Inhibition of Premixed and Non-Premixed Flames with Fine Droplets of Water and Solutions, Proc. Combust. Inst. 29:369-376, http://dx.doi.org/10.1016/S1540-7489(02)80049-9

[12] Ndubizu, C.C., Ananth, R., and Tatem, P.A., (2000) The Effects of Droplet Size and Injection Orientation on Water Mist Suppression of Low and High Boiling Point Liquid Pool Fires, Combust. Sci. Tech. 157:63-86, http://dx.doi.org/10.1080/00102200008947310

[13] Chang, J.-C., Lin, C.-M., and Huang, S.-L., (2007) Experimental Study on the Extinction of Liquid Pool Fire by Water Droplet Streams and Sprays, Fire Safety J. 42:295-309, http://dx.doi. org/10.1016/ j.firesaf.2006.11.008

[14] Zegers, E.J.P., Williams, B.A., Sheinson, R.S., and Fleming, J.W., (2000) Dynamics and Suppression Effectiveness of Monodisperse Water Droplets in Non-Premixed Counterflow Flames, Proc. Combust. Inst. 28:2931-2937, http://dx.doi.org/10.1016/S0082-0784(00)80718-3

[15] Chelliah, H.K., (2007) Flame Inhibition/Suppression by Water Mist: Droplet Size/Surface Area, Flame Structure, and Flow Residence Time Effects, Proc. Combust. Inst. 31:2711-2719, http:// dx.doi.org/10.1016/j.proci.2006.08.065

[16] Dixon-Lewis, G., David, T., Gaskell, P.H., Fukutani, S., Jinno, H., Miller, J.A., Kee, R.J., Smooke, M.D., Peters, N., Effelsberg, E., Warnatz, J., and Behrendt, F., (1984) Calculation of the Structure and Extinction Limit of a Methane-Air Counterflow Diffusion Flame in the Forward Stagnation Region of a Porous Cylinder, Proc. Combust. Ins. 20:1893-1904.

[17] Chelliah, H.K., Law, C.K., Ueda, T., Smooke, M.D., and Williams, F.A., (1990) An Experimental and Theoretical Investigation of the Dilution, Pressure and Flow-Field Effects on the Extinction Condition of Methane-Air-Nitrogen Diffusion Flames, Proc. Combust. Ins. 23:503-511.

[18] Vandsburger, U., Kennedy, I., and Glassman, I., (1984) Sooting Counterflow Diffusion Flames with Varying Oxygen Index, Combust. Sci. Tech. 39:263-285, http://dx.doi.org/10.1080/ $\underline{00102208408923792}$

[19] Richard, J., Garo, J. P., Souil, J. M., Vantelon, J. P., and Knorre, V. G., (2003) Chemical and Physical Effects of Water Vapor Addition on Diffusion Flames, Fire Safety J. 38:569-587, http:// dx.doi.org/10.1016/S0379-7112(03)00012-2.

[20] Fisher, B.T., Awtry, A.R., Sheinson, R.S., and Fleming, J.W., (2007) Flow Behavior Impact on the Suppression Effectiveness of Sub-10- $\mu \mathrm{m}$ Water Drops in Propane/air Co-Flow Non-Premixed Flames, Proc. Combust. Inst. 31:2731-2739, http://dx.doi.org/10.1016/j.proci.2006.07.023

[21] Fristrom, R. M. and Westenberg, A.A., Flame Structure, McGraw-Hill, 1965, p. 151.

[22] Brock, J.R., (1962) On the Theory of Thermal Forces Acting on Aerosol Particles, Journal of Colloid Science 17:768-780, http://dx.doi.org/10.1016/0095-8522(62)90051-X 